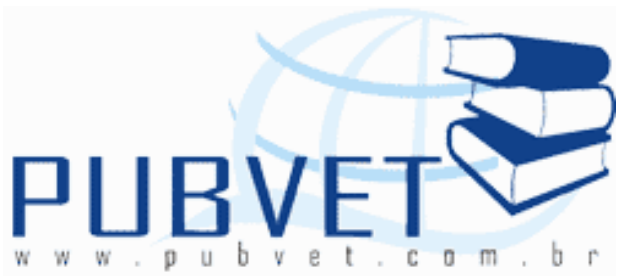

PUBVET, Publicações em Medicina Veterinária e Zootecnia.

\title{
Reabilitação por implantação de cadeira em cão com secção medular torácica como alternativa à eutanásia: relato de caso
}

\author{
Camila Lozano da Silva ${ }^{1}$; Gabriela Bruno Stok Tosato ${ }^{1}$; Jaqueline Neratika \\ Negretti Garcia2; Maria Carolina Gonçalves Pita³
}

\begin{abstract}
${ }^{1}$ Graduanda de Medicina Veterinária da Universidade Guarulhos 2Médica Veterinária, Pós-Graduada em Residência Clínica Cirúrgica de Pequenos Animais da Universidade Guarulhos ${ }^{3}$ Profa Dra Docente da Universidade Guarulhos
\end{abstract}

\section{Resumo}

Os distúrbios da medula espinhal podem ser causados por anomalias, degenerações, neoplasias, traumas, entre outras causas. Lesões traumáticas no canal medular, causadas principalmente por fraturas e luxações da coluna são comuns. O relato de caso apresenta um trauma por atropelamento, onde houve lesão medular grave em que se discute a eficácia do uso de cadeiras de rodas como tratamento alternativo, sem que haja a indicação de eutanásia.

Palavras-Chave: lesão medular, canino, toracolombar. 
SILVA, C.L. et al. Reabilitação por implantação de cadeira em cão com secção medular torácica como alternativa à eutanásia: relato de caso. PUBVET, Londrina, V. 7, N. 26, Ed. 249, Art. 1649, Suplemento 2, 2013.

\title{
Rehabilitation for deployment of wheelchair in dog with thoracic spinal cord section as an alternative to euthanasia: case report
}

\begin{abstract}
Disorders of the spinal cord may be caused by abnormalities, degeneration, neoplasia, trauma, among other causes. Traumatic injuries in the spinal canal, caused mainly by fractures and dislocations of the spine are common. The case's report presents a trauma by running over, where there was severe spinal cord injury that discusses the effectiveness of using wheelchairs as an alternative treatment, without the indication of euthanasia.
\end{abstract}

Keywords: spinal cord injury, canine, thoracolumbar.

\section{INTRODUÇÃO}

A medula espinhal pode ser dividida em 4 porções: cervical cranial (C1C5), intumescência cervical (C6-T2), toracolombar (T3-L3) e intumescência lombar (L4-S3) (TAYLOR, 2010).

Os distúrbios da medula espinhal podem ser causados por anomalias, degenerações, neoplasias, traumas externos, internos, entre outras causas. Lesões traumáticas no canal medular, causadas principalmente por fraturas e luxações da coluna são comuns (TAYLOR, 2010).

Entre as causas de trauma em cães, o atropelamento por veículos automotivos é tido como a mais prevalente (MENDES e ARIAS, 2012; FIGHERA et al., 2008; KOLATA et al., 1974).

As fraturas ou luxações traumáticas são induzidas por forças que resultam em graus graves de hiperextensão, hiperflexão, compressão ou rotação. Estes ocorrem na junção de segmento vertebral móvel com outro imóvel, ou nas proximidades. Quando as forças do impacto do trauma são aplicadas na coluna vertebral, esta relação estático-cinética da coluna espinhal resulta em uma tensão destes locais (SLATTER, 1998). 
SILVA, C.L. et al. Reabilitação por implantação de cadeira em cão com secção medular torácica como alternativa à eutanásia: relato de caso. PUBVET, Londrina, V. 7, N. 26, Ed. 249, Art. 1649, Suplemento 2, 2013.

Fraturas podem envolver qualquer parte da coluna vertebral, compreendendo os corpos vertebrais, processos transversos e espinhosos. Geralmente as fraturas de corpos vertebrais podem vir acompanhadas de alinhamento anormal da coluna principalmente em segmento lombar (SANTOS et al., 2006).

A partir da realização do exame neurológico completo, que compreende avaliação das reações posturais, propriocepção, força, tônus muscular e dos reflexos espinhais é possível identificar o foco de lesão medular (TAYLOR, 2010). A localização da lesão será baseada nos sinais alterados de neurônio motor superior (NMS) e neurônio motor inferior (NMI) que o animal apresente. Em geral, lesões de NMS produzem espasticidade muscular e hiperreflexia, e as lesões de NMI produzem paresia flácida e hiporreflexia (GONZÁLEZ, 1999).

Lesões medulares entre T3-L3 causam paresia e ataxia relacionadas com o NMS nos membros pélvicos, sem acometer os membros torácicos. Nos membros pélvicos nota-se a presença de incoordenação da marcha, perda de propriocepção consciente, maior tônus muscular e reflexos normais ou aumentados, porém quanto mais grave for à lesão neste segmento mais déficits neurológicos o animal irá apresentar. Os cães acometidos por lesões graves podem apresentar postura de Schiff-Scherrington (hipertonia extensora dos membros torácicos- indicativo de lesão severa em segmento toracolombar) (TAYLOR, 2010).

Após uma secção completa da medula espinhal, qualquer recuperação de função que ocorra deve-se a uma reorganização na medula espinhal por formação de novas ligações pelos neurônios aferentes que entram na medula espinhal através das raízes dorsais. Sendo assim, existe a possibilidade de longo período para alterar o comportamento motor de pacientes com secção completa da medula espinhal e permitir a reaquisição de marcha. Em pacientes com parte da medula lesada, a recuperação pode resultar de reorganização 
SILVA, C.L. et al. Reabilitação por implantação de cadeira em cão com secção medular torácica como alternativa à eutanásia: relato de caso. PUBVET, Londrina, V. 7, N. 26, Ed. 249, Art. 1649, Suplemento 2, 2013.

caudal ao local da lesão ou de reorganização das ligações contralaterais não lesadas (JEFFERY e BLAKEMORE, 1999).

Os sinais clínicos presentes em um trauma externo são geralmente associados a sinais agudos e não progressivos. A presença de dor e outras evidências do trauma como hematomas, lacerações, abrasões são característicos (TAYLOR, 2010; FIGHERA et al., 2008).

O animal que apresenta risco de vida devido a choque ou alterações secundárias ao trauma deve ser estabilizado e contido para evitar manipulação inadequada enquanto não se reconhece o foco de fratura e lesão medular (STURGES e LECOUTEUR, 2007).

O diagnóstico deve ser estabelecido pelo histórico de trauma, achados de exame físico e exame neurológico. Para complementar o diagnóstico, podem ser usados dois parâmetros: escala visual analógica e escala de coma de Glasgow modificada. A escala visual analógica conhecida por EVA, tem por objetivo classificar a intensidade de dor do paciente (GAYNOR e MUIR, 2009). Já a escala de coma de Glasgow foi modificada da medicina humana para a veterinária a fim de mensurar o nível de consciência dos animais com dano cerebral (ANDRADE et al., 2010).

Os exames de imagem por sua vez, como as radiografias são precisas para localizar a lesão, verificar o grau do dano e presença deslocamento vertebral. Outros exames de imagem podem ser realizados como tomografia computadorizada, ressonância magnética e mielografia, estes devem ser realizados quando as lesões observadas não correspondem aos achados radiográficos (STURGES e LECOUTEUR, 2007).

O corpo vertebral pode ser dividido em 3 compartimentos, quando 2 ou 3 compartimentos apresentam danos ou estão deslocados, a fratura é considerada instável, estas requerem intervenção cirúrgica para estabilização, 
SILVA, C.L. et al. Reabilitação por implantação de cadeira em cão com secção medular torácica como alternativa à eutanásia: relato de caso. PUBVET, Londrina, V. 7, N. 26, Ed. 249, Art. 1649, Suplemento 2, 2013.

quando as fraturas são estáveis devem ser tratadas de forma conservativa (TAYLOR, 2010).

Para o tratamento, é fundamental estabilização dos animais em risco de óbito, com manipulação cuidadosa, em gaiolas acolchoadas; deve-se realizar movimentação dos membros, mudanças de decúbito para evitar formações de escaras, e forçar o esvaziamento vesical (quando houver infecções urinárias as mesmas devem ser tratadas); deve-se ainda realizar tratamento sintomático, assim como o uso de corticosteroides (sendo o mais utilizado metilprednisolona por seu efeito neuroprotetor) e opioides para analgesia (TAYLOR, 2010).

O tratamento cirúrgico de traumatismo espinhal deve ser realizado em caso de compressão contínua de medula espinhal, realinhamento e estabilização das vértebras. O tratamento cirúrgico proporciona a melhor oportunidade para a recuperação rápida e completa em pacientes com compressão ou instabilidade contínua, e facilita o tratamento, pois fica minimizado o risco de novas lesões resultantes da movimentação da coluna vertebral instável (ETTINGER e FELDMAN, 1997).

O prognóstico é variável dependendo do grau de acometimento da lesão, variando de bom a ruim. Em geral animais com fratura ou luxação vertebral com perda da percepção de dor profunda e ausência de sinais evidentes de melhora após 21 dias está associada a mau prognóstico de recuperação (TAYLOR, 2010).

Sendo assim, as consequências do traumatismo medular, dependendo do segmento lesionado, podem levar à incapacidade permanente, morte (ARIAS et al., 2007) ou eutanásia (BERGMAN, 2000).

O objetivo deste trabalho é indicar uma alternativa as eutanásias, em casos de lesões graves medulares, com secção de medula, a partir do uso de carros/cadeiras de rodas que devolvem ao animal a capacidade de movimentação, proporcionando uma melhor qualidade de vida. 
SILVA, C.L. et al. Reabilitação por implantação de cadeira em cão com secção medular torácica como alternativa à eutanásia: relato de caso. PUBVET, Londrina, V. 7, N. 26, Ed. 249, Art. 1649, Suplemento 2, 2013.

\section{RELATO DE CASO}

A paciente da espécie canina, SRD (sem raça definida), fêmea, cinco anos deu entrada no Hospital Veterinário da Universidade Guarulhos com histórico de trauma automobilístico há cerca de 24 horas. Proprietário relatou que animal foi levado em colega onde se fez o diagnóstico de luxação coxofemoral e fratura de coxal. Proprietário também referiu que animal estava apresentando anúria desde o trauma.

Ao exame físico observaram-se mucosas róseas, pulso forte, em taquicardia e taquipneia, temperatura de $37,6^{\circ} \mathrm{C}$ (graus Celsius), auscultação cardiopulmonar sem alterações, palpação abdominal com sensibilidade, glasglow quatorze e escala visual analógica igual a oito. Durante exame físico animal se apresentava em postura de Schiff-Sherrington. Ao exame neurológico, apresentou ausência de dor superficial, ausência de dor profunda, ausência de reflexo patelar e ausência de reflexo isquiático em ambos os membros posteriores.

No atendimento imediato foi realizado acesso venoso em veia cefálica com a administração de fluidoterapia e analgesia com opioides. Foram realizados exames complementares como glicemia (com resultado de 113 $\mathrm{mg} / \mathrm{dl})$, lactato sanguíneo $(4,1 \mathrm{mmol} / \mathrm{L})$, sondagem uretral (realizada com sucesso e com presença de hematúria), radiografia torácica (sem alterações), radiografia da coluna de região toracolombar (apresentando deslocamento cranial de T12 em relação a T11 (Fig. 1) - luxação completa de corpo vertebral com provável seç̧ão medular) (Fig. 2), hemograma completo (sem alterações), FAST (peritonite focal em topografia de rim direito). Realizado infusão contínua de Morfina + Lidocaína + Ketamina (MLK) para controle da dor. 
SILVA, C.L. et al. Reabilitação por implantação de cadeira em cão com secção medular torácica como alternativa à eutanásia: relato de caso. PUBVET, Londrina, V. 7, N. 26, Ed. 249, Art. 1649, Suplemento 2, 2013.

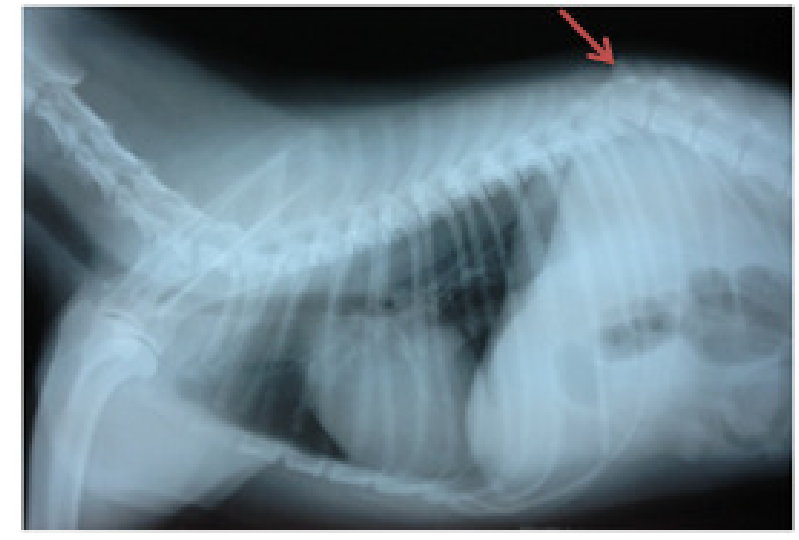

Fig.1: Deslocamento dorso cranial de T12 em relação a T11 (seta) (HOVET UNG, 2012).

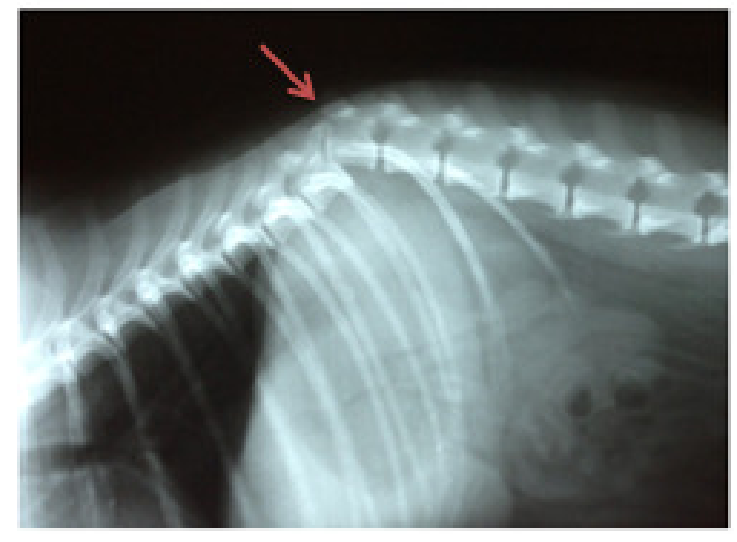

Fig.2: Luxação de corpo vertebral (seta) (HOVET UNG, 2012).

Indicou-se a provável seç̧ão medular e o prognóstico ruim, sendo que o animal necessitaria de manejo específico em casa com massagem vesical periodicamente, alimentação pastosa, trocas periódicas de decúbito evitando formação de escaras.

Animal permaneceu internado para realização de analgesia adequada e controle da peritonite focal. Utilizou-se Enrofloxacina (10mg/kg SID), Dexametasona (1 mg/kg SID), Dipirona (25 mg/kg TID), infusão contínua de MLK, Lactulona (1,5 ml TID) e alimentação pastosa. Antes da liberação do animal foi realizado novo lactato sanguíneo com redução do valor para 2,2 $\mathrm{mmol} / \mathrm{L}$.

Após dois dias proprietário retornou relatando grande melhora clínica da paciente. Animal durante a internação não se apresentava mais em SchiffSherrington e se alimentou com a alimentação pastosa. Em nova avaliação do animal, não houve a indicação cirúrgica para a estabilização da luxação vertebral e luxação coxofemoral. O tratamento indicado foi à utilização de cadeira. Animal foi liberado para casa com medicações e manejo adequado.

Proprietário retornou após 15 dias relatando bom estado geral (normorexia, normodipsia, normoquesia e urina sem alterações). Animal 
SILVA, C.L. et al. Reabilitação por implantação de cadeira em cão com secção medular torácica como alternativa à eutanásia: relato de caso. PUBVET, Londrina, V. 7, N. 26, Ed. 249, Art. 1649, Suplemento 2, 2013.

estava sendo manejado de maneira correta em relação à troca de decúbito, alimentação e higiene. Foram realizadas as medidas do animal para solicitação da cadeira.

Proprietário retornou após 4 meses, relatando animal com hematúria; Realizado hemograma completo (sem alterações) e urina tipo I (presença de cistite). Foram prescritas medicações e retorno para reavaliação.

Atualmente a paciente se encontra em bom estado geral, bem adaptada a cadeira, e com boa qualidade de vida.

\section{DISCUSSÃO}

O estudo de Mendes e Arias (2012) aponta que treze animais apresentaram postura de Schiff-Sherrington, sendo que oito deles foram submetidos à eutanásia devido a não recuperação neurológica, dois apresentaram recuperação funcional total, um houve recuperação parcial, e dois morreram. Em contrapartida, o presente estudo evidencia a melhora da postura de Schiff-Sherrington no quadro do animal com aproximadamente 48 horas após o trauma, sem que se fizesse necessária a indicação de eutanásia.

Em um estudo onde foram avaliados 155 cães atropelados, a morte ou razão para eutanásia em $27,7 \%$ dos casos foi o trauma medular (FIGHERA, et al., 2008). Em outro estudo dos, 30 animais com lesão toracolombar e $10 \mathrm{com}$ lesão lombar, $57 \%$ e $70 \%$ morreram ou foram submetidos à eutanásia respectivamente (MENDES e ARIAS, 2012). A partir dessa análise de ambos os autores, pode-se comparar com o atual estudo, onde o animal relatado apresentou trauma medular com secção da mesma, com luxação de vértebras em região toracolombar, evoluindo para melhora do quadro, podendo-se optar por tratamento alternativo e excluindo a possibilidade de indicação de eutanásia. 
SILVA, C.L. et al. Reabilitação por implantação de cadeira em cão com secção medular torácica como alternativa à eutanásia: relato de caso. PUBVET, Londrina, V. 7, N. 26, Ed. 249, Art. 1649, Suplemento 2, 2013.

De acordo com Taylor (2010) é necessária à realização de esvaziamento vesical, pois podem ocorrer infecções urinárias devido à concentração de urina. Este fato se confirma com o estudo, visto que o animal na fase que se encontrava em decúbito lateral passou a concentrar urina, desenvolvendo um quadro de cistite.

Taylor (2010) afirma que o prognóstico é variável dependendo do grau de acometimento da lesão, variando de bom a ruim. Em geral animais com fratura ou luxação vertebral com perda da percepção de dor profunda e ausência de sinais evidentes de melhora após 21 dias está associada a mau prognóstico de recuperação. Entretanto, a paciente do estudo mostrou-se com prognóstico bom, já que se adaptou ao uso da cadeira, devolvendo assim sua qualidade de vida.

\section{CONSIDERAÇÕES FINAIS}

Com base na literatura e no presente estudo, conclui-se que os distúrbios da medula espinhal muitas vezes estão atrelados a traumas, geralmente associados a traumas automobilísticos. Como consequências podem ocorrer fraturas ou luxações vertebrais e lesões medulares. Os sinais clínicos visualizados variam de acordo com a porção de acometimento da coluna. O principal sinal evidente de lesão grave em toracolombar é a postura de SchiffSherrington que não pode ser considerado um fator de prognóstico isoladamente, já que este não serve como principal indicativo de eutanásia. Por isso devem ser levadas em consideração as condições clínicas do animal em geral e as opções de tratamento para que o animal recupere sua qualidade de vida. A cadeira de rodas tem se mostrado efetiva em lesões medulares permanentes, onde na maioria dos casos a principal conduta seria a eutanásia. 


\section{REFERÊNCIAS BIBLIOGRÁFICAS}

ANDRADE, M. B.; COLE, E. F.; NETO, J. E. et al. Escala de coma de Glasgow pediátrica modificada para cães. Arq. Bras. Med. Vet. Zootec., v. 62, n. 1, p. 47-53, 2010.

ARIAS, M. V. B.; SEVERO, M. S.; TUDURY, E. A. Trauma medular em cães e gatos: revisão da fisiopatologia e do tratamento médico. Semina, Ciênc. Agrárias 28:115-134, 2007.

BERGMAN, R. Spinal cord injury. Vet. Med. 95:845, 2000.

ETTINGER, S. J.; FELDMAN, E. C. Tratado de Medicina Interna Veterinária. São Paulo: Manole, p. 890-973, 1997.

FIGHERA, R. A.; SILVA M. C.; SOUZA T. M. et al. Aspectos patológicos de 155 casos fatais de cães atropelados por veículos automotivos. Ciência Rural, Santa Maria, v. 38, n.5, p.1375-1380, ago. 2008.

GAYNOR, J. S.; MUIR, W. W. Manual de controle da dor em Medicina Veterinária. $2^{\mathrm{a}}$ ed. São Paulo: MedVet, p. 643, 2009.

GONZÁLEZ, T. F. Aproximación al diagnóstico de las enfermedades espinales. Em: GONZÁLEZ, T. F. Enfermidades Espinales. Canis et Felis. n. 41, 1999.

JEFFERY, N.D.; BLAKEMORE, W. F. Spinal cord injury in small animals. Mechanisms of spontaneous recovery. Veterinary Record, v.144, p.407-413, 1999.

KOLATA, R.J. et al. Patterns of trauma in urban dogs and cats: a study of 1,000 cases. Journal of the American Veterinary Medical Association, v.164, n.5, p.499-502, 1974.

MENDES, D. S.; ARIAS, M. V. B. Traumatismo da medula espinhal em cães e gatos: estudo prospectivo de 57 casos. Pesq. Vet. Bras. 32(12):1304-13012, dez. 2012.

SANTOS, T. C. C. et al. Principais afecções da coluna vertebral de cães: Estudo Retrospectivo (1995-2005). Vet. e Zootec. v.13, n.2, p. 144-152, 2006.

SLATTER, D. Manual de Cirurgia de Pequenos Animais. São Paulo: Manole, p.1257-1344, 1998.

STURGES, B. K.; LECOUTEUR, R. A. Fraturas e Luxações Vertebrais. Em: SLATTER, D. Manual de Cirurgia de Pequenos Animais. 3a Ed. São Paulo: Manole, vol. 1, p. 1244-1249, 2007.

TAYLOR, S. M. Distúrbios da Medula Espinal. Em: NELSON, R. W.; COUTO, C. G. Medicina Interna de Pequenos Animais. 4a Ed. Rio de Janeiro: Elsevier, p. 1067-1072, 2010. 